\title{
С.М. Климова*
}

\section{Л.Н. ТОЛСТОЙ И В.В. РОЗАНОВ: ДВЕ ИСПОВЕДИ**}

\begin{abstract}
Статья посвящена сопоставлению текстов двух исповедей - «Исповеди» Л.Н. Толстого и «Уединенного» В.В. Розанова - в аспекте их жанровых и содержательных характеристик. В процессе исследования был учтен момент смены литературных стилей, связанный с переходом от реализма Толстого к модернизму, отраженному в жанре «опавших листьев» Розанова. Исповедальность Толстого, созданная на основе классических традиций Августина и Руссо, становится толчком к созданию новых исповедальных форм, например, иронической философии Розанова. При этом оба автора используют прием остранения: Толстой как художественный, а Розанов - как стилистический, необходимый для проявления его иронической философии.
\end{abstract}

Ключевые слова: исповедь, психология личности, остранение, ирония, Л.Н. Толстой, В.В. Розанов

Leo Tolstoy and Vasily Rozanov: two confessions. SVETLANA M. KLIMOVA (HSE University, Moscow)

The article compares two literary texts of confessions - by Leo Tolstoy and Vasily Rozanov. The author takes into account the change of literary styles, associated with the transition from Tolstoy's realism to the modernism reflected in Rozanov's «fallen leaves». Tolstoy's confessionalism, created in line with the tradition of Augustine and Rousseau, becomes the catalyst for the new forms of confession reflected in the ironic philosophy of Rozanov. The text by Tolstoy is a confession of the autonomous self, who strives to overcome his carnal beginning on the way to the spiritualization of the personality. The latter is achieved by estrangement from his social circle, his profession as a writer, his family, that is, from himself for the sake of spiritual salvation. This way is about returning to Christ as a bastion of love and non-resistance to evil, as well as establishing a loving spiritual connection with the world of others. Rozanov's confession is different: it is possible only in the form of an initial unity of the Self with Others: with the world of his family, his wife, friends, readers, and even with the world of things around him. What Tolstoy separates in man and the world - the carnal and the spiritual - Rozanov sees as initially united in any phenomenon. The comparison of two confessions allows us to demonstrate a number of fundamental shifts in philosophy and literature in the early $\mathrm{XX}^{\text {th }}$ century.

Keywords: confession, personality psychology, defamiliarization, irony, Leo Tolstoy, Vasily Rozanov

* КЛИМОВА Светлана Мушаиловна, доктор философских наук, профессор Школы философии и культурологии факультета гуманитарных наук Национального исследовательского университета «Высшая школа экономики».

E-mail: sklimova@hse.ru

(c) Климова С.М., 2021

** Работа выполнена при финансовой поддержке гранта РНФ. Проект №19-18-00100. 
Л.Н. Толстой и В.В. Розанов многие годы находились в общем жизненном и социокультурном пространстве, хотя были людьми разных поколений и по возрасту, и по убеждениям. Они были скорее антиподами, чем единомышленниками. Поэтому правомерно утверждать, что «Исповедь» (1879-1882) Толстого и «Уединенное» (1912) Розанова - две исповеди-откровения - хотя и написаны в общем-то современниками, людьми, лично знавшими друг друга, но как будто бы в совершенно разные эпохи настолько за 30 лет, которые пролегли между двумя произведениями, изменились и эпоха, и литература, и отношение к исповедальной искренности, выраженное в художественных и философских текстах. Между тем, Б.М. Эйхенбаум, определяя «Исповедь» Толстого как руссоистскую по стилю, но не по содержанию, точно заметил, что Толстой был не только завершителем эпохи Просвещения, но и зачинателем новой. Недаром его имя стало путеводной звездой для русских формалистов начала XX в. Идеи формализма нашли отражение в интерпретации учения Толстого у В.Б. Шкловского (остранение) и Б.М. Эйхенбаума (теория литературного быта). М. Деннер показал, как «мастер реалистического романа» Толстой был «захвачен авангардизмом», к которому ученый свел как толстовский поиск «наивной формы» искусства для народа, так и его требование эстетического опрощения. Уточним, что хотя Толстой и был «зачинателем» эпохи модернизма, это не равносильно тому, что он был его сторонником или «приверженцем авангардного искусства» [8, с. 370-388].

В промежутке между появлением двух указанных исповедей произошла кардинальная смена литературных форм, нарушившая логику «школьной» преемственности развития от одного эстетического направления к другому. Теперь оно шло «не от отца к сыну, но от дяди к племяннику» [7, с. 322]. В этом нарушении разговора об интимной прозе как движения от Руссо к Толстому и от Толстого к Розанову и рождается новый тип литературы - «опавшие листья», исповедальный текст Розанова, связанный и не связанный как с традициями толстовской «Исповеди», так и с поиском новых форм описания внутренних переживаний автора/героев.

Сознательно или бессознательно, но Розанов, как и практически вся русская интеллигенция в конце XIX - начале XX вв., находился под влиянием учения и эстетики Толстого. Прямым доказательством можно считать его многочисленные статьи о писателе [3] и непрерывную полемику с ним, главным образом на страницах тогдашней российской периодики. Известно и о его посещении Ясной Поляны в марте 1907 г., об их взаимном неприятии и недопонимании друг друга - как после этой поездки, так и в ходе заочного обмена мнениями об идеях и убеждениях друг друга.

Так или иначе, Толстой был важен для Розанова и как писатель, и как религиозный мыслитель, и как «совесть нации». Он был тем берегом, отталкиваясь от которого Розанов оттачивал свой уникальный взгляд на философию пола, семьи и религии и создавал новую литературу.

Сопоставляя две исповеди, мы должны указать на их жанровую общность. В жанровом смысле оба автора нарушили канон использования слова «исповедь», отсылающий к религиозному контенту и традициям ее рассмотрения как важнейшего таинства, имеющего место в литургической практике. Литературная исповедь обоих очень условно может быть названа религиозным «таинством», ведь она полностью открыта, десакрализована для любого желающего к ней прикоснуться. Литературная исповедь начиная с XVII-XVIII вв. воспринимается как автономный (художественный, публицистический и даже религиозный) текст, направленный на выражение интимного мира переживаний его героев, а не на покаяние, прощение или причащение по церковному типу.

В обоих случаях перед нами литературные исповеди, насыщенные элементами автобиографизма. Для обоих биография - это лишь повод к самообнажению. Ни «Исповедь» Толстого, ни «Уединенное» Розанова нельзя считать биографическим текстом в традиционном смысле слова «биография». Несмотря на то, что оба текста наполнены фактами из жизни их авторов, понимать их биографичность следует лишь условно, как прием для описания психологии саморазоблачения и покаяния. Биография здесь уже обработана критической мыслью автора, литературна по сути, и каждый биографический факт неразрывно связан с покаянной логикой исповедующегося автора. Не понимая этого, читатель и впрямь может подумать, что Толстой «убивал людей», как разбойник, а не как воин, «учил, сам не зная чему» в своих великих произведениях; или читатель вдруг наивно 
начинает передавать приветы милой жене Розанова, не понимая условности образа «друга» в его тексте и разницы между ней и той Варварой Дмитриевной Бутягиной, которая была женой писателя [2, с. 53-65].

В исповедальных текстах Толстого и Розанова есть обязательные для данного жанра элементы интимности, откровения, покаяния; многие из них связаны с генеральной идеей направлены на саморазоблачение исповедующихся авторов. Исповедующийся автор - некий психологический тип личности, находящийся в пограничном состоянии экзистенциального кризиса («остановки жизни», по словам Толстого), разлада между собой и миром до такой степени отторжения, что единственным способом его преодоления становится настоятельная потребность выговориться - то есть озвучивание своего внутреннего мира миру внешнему. Такое состояние Розанов назвал «святой проституцией», когда «самое интимное - отдаю всем», добавив иронически, что за такое сравнение можно и убить, а можно и «бесконечно задуматься» [4, с. 44], то есть сделать основой новой философской рефлексии.

Разница же исповедей в том, что Толстой разоблачается всерьез, он открывает миру не только себя в «преступных состояниях» войны, тщеславия или учительства. Одновременно он открывает миру и преступность войны как таковой, уже безотносительно к самому себе, и пустоту позиции любого современного ему писателя, и иллюзорность многих ценностей, которыми так дорожит человек и которые основаны на эксплуатации и присвоении плодов чужого труда. Розанов же ироничен в своих разоблачениях от начала до конца. В его творчестве четко различаются Розанов-автор и Розанов-герой. Впервые в русской философии появился герой-обыватель и герой-философ обывательской жизни. Розанов-философ добровольно создает миф о Розанове-герое, вводя читателя в искушение непонимания этого различия и одновременно принципиально меняя направление исповедальной литературы в ХХ в.

Оба автора делятся своими откровениями не только с читателем, но и со всем миром. «Исповедальный текст всегда замкнут и разомкнут одновременно, что позволяет воспринимать его и как становящееся внутри себя единство, и как универсальное обращение к человечеству, послание последующим поколениям» [5, с. 116]. Однако, если универсализм Толстого ясно отра- жен в его обращении к своим современникам, и в этом смысле он, подобно Ж.-Ж. Руссо, пишет для современников, то Розанов сразу же уточняет безадресную и вневременную логику своего текста, указывая на то, что читатель как адресат его давно не волнует («К черту» читателя). Его текст обращен к вневременному миру идеальных собеседников, написан для всех времен и народов и ни для кого конкретно. Главный герой и «другой» этого текста - сам В.В. Розанов во всей красе откровений, порой «интимных до оскорблений» (Шкловский), полностью самообнажающих душу исповедующегося. «Слова у него не символы мысли, а плоть и кровь» $[1$, c. 349]. В этом аспекте важно подчеркнуть, что ницшеанская тенденция писать «для всех и ни для кого» - квинтэссенция исповедального текста Розанова, «биологического и полнокровного» (Н. Бердяев) по сути.

Сравнивая исповедальные тексты Толстого и Розанова, следует сказать и об их принципиальных отличиях. Исповедь Толстого развивает прежде всего религиозные традиции Августина и просветительские взгляды Руссо. Важнейшим здесь является экзистенциальный кризис, отраженный в неверии в себя, свою прежнюю жизнь, материальное благополучие, семью и т.д., то есть - потеря смысла жизни, а по сути - потеря веры в Бога как в основание жизни. Одновременно это и поиск способов и путей его обретения, то есть возвращение к смыслу жизни. В «Исповеди» Толстой сделал самого себя почти типичным примером возможного перерождения человека, преодолевшего свое животное Я на пути к Я духовному или всечеловеческому. Толстой показал свой путь остранения от самого себя социально-политического (активного члена общества: офицера, писателя, семьянина) к себе «простаку», религиозному человеку «народного типа мировоззрения», услышавшему голос Бога в себе и поверившему в Его Слова, прямо, буквально воспринимая смысл им сказанного. «Христос ничего не преувеличивает и не требует никаких страданий для страданий, а только очень определенно и ясно говорит то, что говорит... и мне стало удивительно, как мог я так навыворот понимать ясные, определенные слова» [6, с. 311$]$.

Остранение как художественный прием срастается здесь у Толстого с исповедальной формой письма - искренностью выражения чувств и мыслей, не позволявшей его уму и сердцу лгать перед лицом очевидного противо- 
речия: между тем, что он видел, и тем, что он чувствовал и понимал (или не понимал) в происходящем. Исповедь - это и есть остранение от себя внешнего (животного), живущего по законам общепринятого. Она помогла Толстому услышать в себе иного - духовного человека, который есть подлинное Я, находящееся внутри каждого из нас.

Главная задача его исповеди - привести любого человека к духовному перерождению, понятому многими его современниками как вульгарный призыв к опрощению. Способность перевести регистр интересов с себя (своего эгоистического и животного Я) и своей дворянской культуры как лучшей (на самом деле - ширмы для поддержания своего животного Я) на другого есть первый шаг на пути выхода в иное измерение общей жизни. Но чтобы выйти из автоматизма своей культурной бессознательной жизни, наполненной любовью к себе, нужна рефлексия и душевная эмпатия, то есть нужно еще более мощное основание для обнаружения в себе другого. Этим универсальным Другим для Толстого стала его религиозная вера и практика жизни по Христу. Вера и практика религиозной жизни требуют усиленной работы сознания - силы жизни и разумного понимания ее законов.

В этом пункте Толстой и Розанов - принципиальные антиподы. Толстой пытается преодолеть свой субъективизм в идее универсального духовного Я. Розанов, напротив, настоятельно выступает с апологией плотского, вещного, материального, семейного человека. В отличие от Толстого он не разделяет, а соединяет плотское и духовное, феноменальное и ноуменальное в человеке, защищая те «две капли меда», от которых так истово отрекался Толстой. Для него Бог-Друг-Другие - это единый неразрывный семейный мир, куда попадает и мир вещей. Благодаря этому приему «рюшечки и слоники» семейного обывательского дома не опошлились, как у А.П. Чехова, не высмеивались, как у М.М. Зощенко, а обретали подлинное духовное наполнение, очеловечивались, войдя в космос жизни - в круг его религии семьи. Внутри мира вещей происходит борьба памяти со смертью за человека ${ }^{1}$, к ним прикасавшегося или их но-

\footnotetext{
${ }^{1}$ Мир вещей, вбирающих в себя память о человеческом в зачеловечном мире Колымы и одновременно о бесчеловечном мире советской официальной жизни, поразительным образом передан в трагической прозе В.Т. Шаламова.
}

сившего; борьба семьи против мертвого слова интеллигенции, церкви или псевдокультуры о правах матери, ребенка, Бога.

С этой точки зрения Толстой и Розанов представляют два разных типа оппозиции и связи Я и Бога. Толстой - один на один с проблемой животного страха смерти, психологией восприятия своей жизни как греха, этикой потерь и экзистенцией обретения подлинного смысла жизни. Он переживает глубочайший экзистенциальный кризис разрыва своей связи с миром. Метафорой его безосновности в этот период стал описанный в «Исповеди» сон: «Вот этот сон: Вижу я, что лежу на постели. ... Я спрашиваю себя: где я и на чем я лежу? И начинаю оглядываться и прежде всего гляжу вниз, туда, куда свисло мое тело, и куда, я чувствую, что должен упасть сейчас. Я гляжу вниз и не верю своим глазам. Не то что я на высоте, подобной высоте высочайшей башни или горы, а я на такой высоте, какую я не мог никогда вообразить себе» $[6$, с. 57-58]. Из этого висения Толстой может выйти только сам, один, с помощью такого же единичного Бога, который - Все для него - его Другое.

Розанова одного как будто бы и нет вовсе в его исповедальной прозе, несмотря на слова о страшном вечном одиночестве и утробности духовного существования. Его одиночество, как и кризис, не совсем экзистенциальные. Он боится не себя потерять в мире, а потерять мир вне себя. Поэтому страх смерти для него - это страх не за себя, а за другого - за свою жену, за ее возможный преждевременный уход. Боязнь потери Бога - это боязнь потери семьи с ее миром людей и вещей, с ее возможной потерей памяти, личных писем, «листьев воспоминаний» о голосе, жесте, интонаций - важных составляющих любви, которые бесследно исчезают в цивилизационных жерновах монстра Гуттенберга, появлении пластинок для записей и других убивающих мелочах цивилизации. Без этого круга шуршащей интимности нет вселенского мира: нет Бога, нет истории, нет мира людей. Называя Варвару Дмитриевну своим другом, он тотчас намекает на другого Друга - на Бога и показывает равнозначность единичной и всеобщей жизни и смерти, друга и Другого. В этой равнозначности заключена и вера в Воскресение, и тождество Бога и Человека - единство плотского и духовного, земного и небесного. Жить, умирать и воскресать ни без друга, ни без Бога, ни без шума вентилятора он не может и не хо- 
чет. Для него, как и для Толстого, Бог - это основание и столп, но не его самого, а всего космоса семьи, совпадающего с религией жизни.

В логике изложения Розанова также используется прием остранения, но как иронический, как способ самообнажения, резко контрастирующий с толстовским. Толстой откровенен всерьез, например, разоблачая себя как воина, писателя или как семьянина, а Розанов, обнажаясь, раскрывая свои «пошлые интимности», словно ерничает над миром в своей всеразрушающей самоиронии, насмешке. Тем самым происходит подмена самокритики на самовосхищение и самоодобрение, открываемое в его самых одиозных пассажах. Ирония исповедальных текстов Розанова обрушает и всю серьезность классики, в том числе - толстовской исповеди. На исповедальный трагизм самообнажения русского гения Розанов накладывает иронически-обывательский скепсис трудящегося, философа, думающего о насущном хлебе, а не о высоких идеях. Таким образом Розанов выражает и недоверие к уже завершившей свой классический круг литературной исповеди: его жанр - это оппозиция всей исповедальной литературе в принципе. Разрушить оказалось легко, вместо слез выставляя саркастическую улыбку, боль разбавляя «цинизмом», который, по словам Розанова, и есть новая форма выражения страдания $[4$, с. 83]: без фальши культурных ширм и серьезно-умного отношения к обсуждаемому. Толстой мечтал о литературе вне фальши иллюзорных ценностей, Розанов показал изнаночную сторону этой мечты.

Вспомним Розанова: «Толстой прожил собственно глубоко пошлую жизнь» [4, с. 161]. Эта фраза стала квинтэссенцией вульгарного принципа поведения толпы, на котором было построено всеобщее шельмование великого человека всей сворой дельцов и обывателей - «Добчинских» от философии, прессы, литературы, религии. Почти не заметна циническая боль автора, заключенная в этой фразе. На самом деле эта фраза - не убеждение автора, а собирательное мнение толпы, схваченное им в ней. Розанов лишь маркирует общую для модерна тенденцию иронического разрушения образа Толстого, превращения мира его искренних страданий и саморазоблачения в бульварный способ посмеяться над великим человеком, заработать себе славу на его имени, «хайпануть», как сказали бы сегодня. Это Добчинские, которые кричат на всех углах о слабостях и пороках других, зарабатывая очки даже на чужих смертях, но лишь для того, чтобы о них узнали, как великолепно заметил писатель [4, с. 107]. Розанов указывает нам, что эпоха принципиально изменилась. Толки сменились толковищем; на смену критике пришли пиар-технологии начала XX в.: анекдоты, вульгарные заметки в прессе, бесконечное тиражирование фотографий Толстого, выставленных в окнах модных магазинов для «рекламы» одежды, например; скандальное поведение папарацци около Ясной Поляны и любых публичных мест, где бывали Толстые, и тому подобные штучки стали тем миром, который в модернизме и постмодерне оказывается тождественен трем словам: «Лев Николаевич Толстой».

В иронической философии Розанова была изменена сама природа исповедального слова в литературе, изменен статус русского писателя. Напомним, что эта тема задевала и Толстого, и Розанова с одинаковой силой; оба жаждали критического преображения русского писателя. Однако Толстой отрекается от своего писательства и встает на точку зрения народа, пытаясь подражать ему не только в практике жизни, но и в жанровом смысле, создавая сказки, простые поучительнее рассказы, житийные истории и т.д. Он остраняется от своей сути ради приближения к народу - умения говорить его языком. Розановская форма письма иная. Она уроднена ему без всякого отречения; при этом он утверждает новое слово о литературе и ее героях. Розанов стремится сделать героями обывателей, и в этом он и его герои совпадают. Его мир - это мир обывателей, мещан, людей, выучившихся на медные деньги и вставших на путь трудового преображения жизни. Жанр «опавших листьев» - единственный на то время позволявший говорить о частном человеке-труженике, у которого и языка-то своего для разговора не было в отличие от русского мужика. Розанов неоднократно описывает оппозицию проституирующего слова писателя и святого молчания рядовых тружеников как базовую в современной ему культуре. Его цель - дать им язык, заговорить от их имени о жизни как она есть - с ее радостью, болью, кисеей на подушках и т.д. и показать, что Бог живет в каждом уголке не только сердца, но и дома, мира вещей, несущих память об этих молчаливых святых тружениках.

Если Толстой ищет Бога как опору для всеединства и разумного соединения всех в единый 
океан любви, то для Розанова Бог - это максимально близкий и родной образ, он - почти то же самое, что и его личные вещи, его семья и друзья. Мир вещей, жизнь, труд, семью он соединяет через единство феноменального и ноуменального в свою религию пола и семьи.

\section{СПИСОК ЛИТЕРАТУРЫ}

1. Бердяев Н.А. Собрание сочинений: в 3-х т. Т. 3. Париж, 1989.

2. Климова С.М. Проблемы поэтики Достоевского-Розанова-Бахтина // Человек. 2004. № 3. С. 53-65.

3. Розанов В.В. Собрание сочинений: в 30-ти т. Т. 4. О писательстве и писателях. М.: Республика, 1995.

4. Розанов В.В. Полное собрание «опавших листьев». Кн. 1. Уединенное. М.: Русский путь, 2002.

5. Салманова И.Ф. Переписка как исповедально-диалогическое пространство русской культуры // Н.Н. Страхов в диалогах с современниками. Философия как культура понимания / Под ред. С.М. Климовой. СПб: Алетейя, 2010. С. 116-135.

6. Толстой Л.Н. Полное собрание сочинений: в 90 т. Т. 23. М.: Государственное издательство «Художественная литература», 1957.

7. Шкловский В.Б. Розанов // Розанов В.В.: pro et contra. Кн. 2. СПб.: РХГА, 1995. С. 321343.

8. Denner, M.A., 2008. Dusting off the couch (and discovering the Tolstoy connection in Shklovsky's «art as device»). The Slavic and Eastern European Journal, Vol. 52, no. 3, pp. 370-388.

\section{REFERENCES}

1. Berdyaev, N.A. 1989. Sobranie sochinenii: v 3-kh t. T. 3 [Collected works: in 3 volumes. Vol. 3 ]. Paris. (in Russ.)

2. Klimova, S.M. 2004. Problemy poetiki Dostoevskogo-Rozanova-Bahtina [Problems of the poetics of Dostoevsky-Rozanov-Bakhtin], Chelovek, no. 3, pp. 53-65. (in Russ.)

3. Rozanov, V.V., 1995. Sobranie sochinenii: v 30-ti t. T. 4. O pisatel'stve i pisatelyakh [Collected works: in 30 volumes. Vol. 4. On writing and writers]. Moskva: Respublika. (in Russ.)

4. Rozanov, V.V., 2002. Polnoe sobranie «opavshikh list'ev». Kn. 1. Uedinennoe [Fallen leaves. Solitaria]. Moskva: Russkii put'. (in Russ.)

5. Salmanova, I.F., 2010. Perepiska kak ispovedal'no-dialogicheskoe prostranstvo russkoi kul'tury [Correspondence as a space for confession and dialogue in Russian culture]. In: Klimova, S.M. ed., 2010. N.N. Strakhov v dialogakh s sovremennikami. Filosofiya kak kul'tura ponimaniya. Sankt-Peterburg: Aleteiya, pp. 116-135. (in Russ.)

6. Tolstoy, L.N., 1957. Polnoe sobranie sochinenii: v 90 t. T. 23 [The complete collected works: in 90 volumes. Vol. 23]. Moskva: Gosudarstvennoe izdatel'stvo «Khudozhestvennaya literatura». (in Russ.)

7. Shklovsky, V.B., 1995. Rozanov [Rozanov]. In: Rozanov V.V.: pro et contra. Kn. 2. SanktPeterburg: RKhGA, 1995, pp. 321-343. (in Russ.)

8. Denner, M.A., 2008. Dusting off the couch (and discovering the Tolstoy connection in Shklovsky's «art as device»). The Slavic and Eastern European Journal, Vol. 52, no. 3, pp. 370-388.

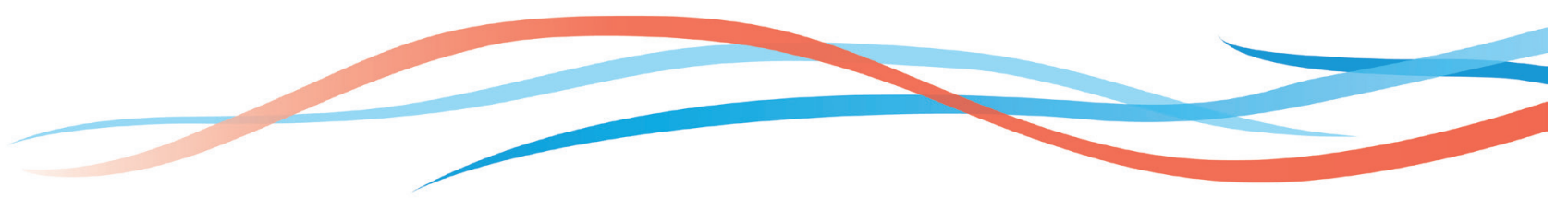

